\title{
Overall kinetics of photosystem II: pH dependence and deuterium isotope effect
}

\author{
Ulrich Krohs ${ }^{\star}$ and Helmut Metzner $\star \star \star$ \\ Institut für Chemische Pflanzenphysiologie der Universität Tübingen, Corrensstr. 41, D-7400 Tübingen \\ (F.R.G.) \\ (Received 5 November 1989)
}

\section{ABSTRACT}

The overall kinetics of photosystem II was scanned by means of a double flash technique. Oxygen evolution by pea thylakoids provided with an artificial electron acceptor was measured under a regime of double flashes of variant intervals. The $\mathrm{pH}$ optimum in $\mathrm{H}_{2} \mathrm{O}$ lies near $\mathrm{p}^{1} \mathrm{H} 7.2\left(\mathrm{p}^{1} \mathrm{H}\right.$ meaning the $\mathrm{pH}$ in $\mathrm{H}_{2} \mathrm{O}$ ), with a first-order rate constant of $800 \mathrm{~s}^{-1}$ at $20^{\circ} \mathrm{C}$. In deuterium oxide $\left(\mathrm{D}_{2} \mathrm{O}\right)$, a plateau of maximum reaction rate was found between $\mathrm{p}^{2} \mathrm{H} 6.6$ and $7.8\left(\mathrm{p}^{2} \mathrm{H}\right.$ meaning the " $\mathrm{pH}$ " in $\left.\mathrm{D}_{2} \mathrm{O}\right)$, the highest rate constant being $550 \mathrm{~s}^{-1}$. The apparent kinetic deuterium isotope effect is therefore 1.45. Outside this plateau region, there seems to exist another isotope effect of 1.2 to 1.3. These effects are small but may nevertheless reflect the fact that more than one step of the photosystem II reaction sequence is involved in the splitting of a bond to hydrogen. However, the effects may also be solvent effects or located on the acceptor side of the photosystem.

\section{INTRODUCTION}

The action of photosystem II (PS II) of higher plants, algae and cyanobacteria corresponds to the action of a hypothetical light-driven water: plastoquinone oxidoreductase. PS II is regarded as the only source of molecular oxygen in the atmosphere. Today a vast amount of data is available on almost any aspect of photosynthesis, and many of the involved reactions are well studied and understood.

\footnotetext{
${ }^{\star}$ Presented at the 10th Bioelectrochemical Conference (BEC X), Pont-à-Mousson (France), 24-30 September 1989.

$\star \star$ Present address: Institut für Biologische Informationsverarbeitung, Forschungszentrum Jülich GmbH, Postfach 1913, D-5170 Jülich, F.R.G.

$\star \star \star$ To whom correspondence should be addressed.

0302-4598/90/\$03.50 @ 1990 - Elsevier Sequoia S.A.
} 
Nevertheless, the mechanism of water oxidation remains obscure. The polypeptide structure of the oxygen evolving complex (OEC) is well known, as is the presence of four or three $\mathrm{Mn}$ ions in the active center and the requirement for several ions, e.g. $\mathrm{Ca}^{2+}, \mathrm{HCO}_{3}^{-}$and $\mathrm{Cl}^{-}$[1]. Electron paramagnetic resonance studies [2] and X-ray spectroscopy $[3,4]$ have revealed some features of the geometric structure of the center and led to mechanistic models.

Another approach, which complements structural investigations, is reaction kinetics. The overall kinetics of the PS II reaction sequence was investigated by several groups using different techniques [5-8]. First-order rate constants between 800 and $1150 \mathrm{~s}^{-1}$ were found. Kok et al. [9] showed that the OEC, kinetically the M system, works with a linear four-step mechanism, accumulating four positive charges per reaction center by stepping through the so-called $S$ states before releasing one molecule of molecular oxygen. Since then, the rate constants of these four steps have been determined [10], as have the constants for other steps on the donor and acceptor sides of PS II (Fig. 1).

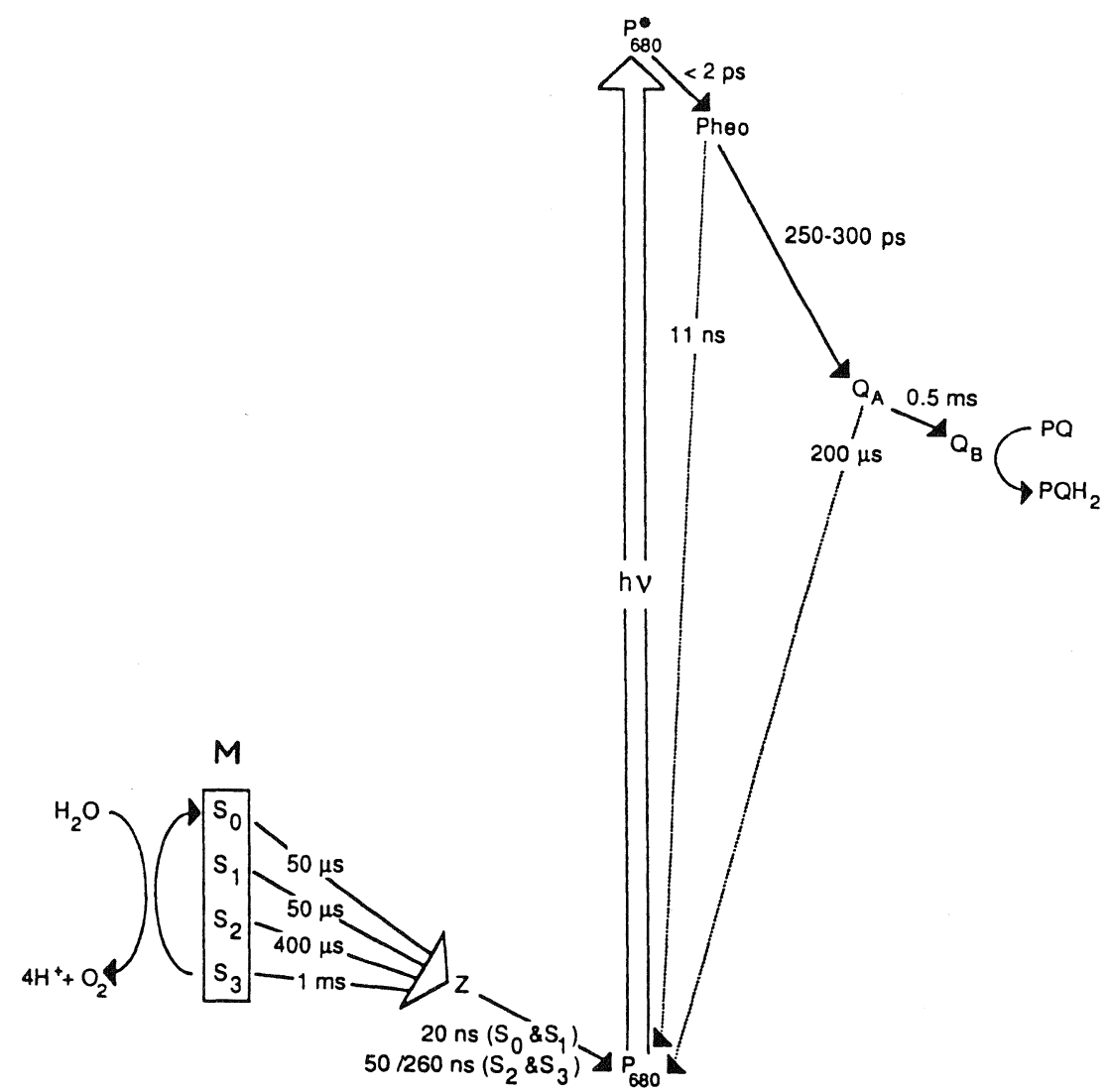

Fig. 1. Kinetic scheme of PS II reactions. Solid lines: foreward reactions. Dotted lines: charge recombinations. Modified after ref. 11. 
However, knowledge of the rate constants under constant conditions does not reveal all information which would in principle be available through this approach. Thus, it seemed worthwhile to investigate the $\mathrm{pH}$ dependence and, secondly, to study the deuterium isotope effect upon the reaction. A deuterium isotope effect should occur, if a bond to hydrogen is broken in the rate limiting step. Since $\mathrm{D}_{2} \mathrm{O}$ is the substrate as well as the solvent in these experiments, there might be an effect due to structural changes of PS II as well. The deuterium isotope effect on the whole photosynthetic electron transport chain has already been determined [12,13], but the rate constants in $\mathrm{H}_{2} \mathrm{O}$ are much smaller than those obtained for PS II alone. So neither the rate constants nor the isotope effect can be attributed exclusively to PS II.

To see whether the chosen approach is promising and in order to obtain first general results on the whole system, it was decided to investigate the overall reaction of PS II rather than single steps. In all experiments, osmotically broken pea chloroplasts, type E chloroplasts according to ref. 14, were used. In the following, they will be called thylakoids for the sake of brevity.

\section{EXPERIMENTAL}

\section{Materials}

Deuterium oxide, 99.8 atom\% D, bovine serum albumin (BSA) Fraction V powder, and gramicidin S were obtained from Sigma. $2^{\prime}, 4^{\prime}$-Dinitrophenylether of 2-iodo-4-nitrothymol (DNP-INT) was a gift of Prof. A. Trebst, Bochum. Pure water was Aqua pro infusione, purchased from Fresenius, Bad Homburg. All other reagents were of analytical grade. Peas, Pisum sativum L. var. Feltham First, were obtained from Lange \& Lehners, Osnabrück.

\section{Methods}

The grinding medium contained $400 \mathrm{mM}$ sucrose, $10 \mathrm{mM} \mathrm{NaCl}, 5 \mathrm{mM} \mathrm{MgCl}{ }_{2}$, $50 \mathrm{mM}$ MOPS and $2 \mathrm{~g} / 1 \mathrm{BSA}$, adjusted to $\mathrm{pH}$ 6.5. The measuring buffer consisted of $200 \mathrm{mM}$ sucrose, $20 \mathrm{mM} \mathrm{NaCl}, 5 \mathrm{mM} \mathrm{MgCl}_{2}$ and $50 \mathrm{mM}$ MOPS or MES, respectively, depending on the desired $\mathrm{pH}$ of the buffer, which was adjusted by addition of $\mathrm{KOH}$. The storage buffer was made from measuring buffer $\mathrm{pH} 7.2$ by addition of $0.1 \%$ BSA (w/v) and then kept on ice. $\mathrm{D}_{2} \mathrm{O}$ buffers were prepared by taking up lyophilized aqueous buffer of the desired $\mathrm{pH}$ in $\mathrm{D}_{2} \mathrm{O}$. This lyophilization procedure was repeated once, since the exchanging hydroxyl protons of the sucrose are the source of a considerable amount of water protons after the first drying procedure. The final lyophilizate was taken up in $\mathrm{D}_{2} \mathrm{O}$ immediately before use. $\mathrm{H}_{2} \mathrm{O}$ buffer was treated in the same way for all measurements which should be compared directly with data from $\mathrm{D}_{2} \mathrm{O}$, using pure water to take up the lyophilizate.

Peas were germinated for three days and then grown in hydroculture (using the medium for spinach hydroculture according to ref. 15) on muslin-covered trays in a light thermostat (Rubarth 1200 ) at $20^{\circ} \mathrm{C}$, under a $16 \mathrm{~h} / 8 \mathrm{~h}$ light/dark regime. After 11 to 13 days from the beginning, 20 to $25 \mathrm{~g}$ of leaves were harvested 1 to $2 \mathrm{~h}$ after 
the onset of illumination, and thylakoids were prepared by the following procedure, which is based on ref. 16. All steps were performed at $0-3^{\circ} \mathrm{C}$, avoiding bright illumination. Leaves were blended for $12 \mathrm{~s}$ in grinding medium. The pulp was squeezed through twelve layers of muslin and centrifuged for $30 \mathrm{~s}$ at $10,000 \mathrm{~g}$. The pellet was resuspended in distilled water to perform osmotic shock and after $5 \mathrm{~min}$ centrifuged for $5 \mathrm{~min}$ at $200 \mathrm{~g}$. The pellet was discarded and the supernatant centrifuged for $5 \mathrm{~min}$ at $2000 \mathrm{~g}$. Thylakoids were resuspended in storage buffer, 0.75 $\mathrm{ml} / \mathrm{mg}$ chlorophyll $(\mathrm{Chl})$. The $\mathrm{Chl}$ content was estimated by a standard procedure [17]. For the transfer to $\mathrm{D}_{2} \mathrm{O}, 3.5 \mathrm{ml}$ of freshly prepared thylakoid suspension, containing about $3 \mathrm{mg} \mathrm{Chl}$, were pelleted at $10,000 \mathrm{~g}\left(30 \mathrm{~s}, 3^{\circ} \mathrm{C}\right)$, washed two times with $\mathrm{D}_{2} \mathrm{O}$ storage buffer, and finally homogenized in $2.3 \mathrm{ml}$ of $\mathrm{D}_{2} \mathrm{O}$ storage buffer, resulting in a $\mathrm{Chl}$ concentration of 0.8 to $1.0 \mathrm{mg} / \mathrm{ml}$. Thylakoids for measurements in $\mathrm{H}_{2} \mathrm{O}$ were treated in the same way, using $\mathrm{H}_{2} \mathrm{O}$ storage buffer.

2,6-Dimethyl-1,4-benzoquinone (DMQ, freshly prepared ethanolic solution) was used as electron acceptor, and DNP-INT (stock solution in DMSO, stored frozen at $-30^{\circ} \mathrm{C}$ ) for blocking the electron transport chain between the two photosystems at the $\mathrm{Q}_{\mathrm{z}}$ site [18]. Generation of a membrane potential was prevented by gramicidin $\mathrm{S}$ (stock solution in ethanol, stored at $-30^{\circ} \mathrm{C}$ ). The reaction mixture was made up by adding thylakoids to the measuring buffer until a final concentration of $25 \mu \mathrm{g}$ $\mathrm{Chl} / \mathrm{ml}$ was reached, and afterwards adding stock solutions of the further components to give final concentrations of $20 \mu \mathrm{M}$ DNP-INT, $1.5 \mathrm{mM}$ DMQ and $7 \mu \mathrm{M}$ gramicidin $\mathrm{S}$, respectively. The reaction volume was $3 \mathrm{ml}$, the proportions of organic solvents were $0.2 \%$ DMSO and $0.6 \%$ ethanol.

Kinetic measurements were done in the steady state using the double flash technique [5]. Saturating flashes of white light of $3 \mu$ s duration at $1 / 3$ peak intensity were produced by two stroboscopes (General Radio Strobotac 1538-A). A first flash forces all reaction centers to proceed in the Kok scheme by one step. Several reactions on different time scales have to be completed before the system has reached the next metastable $S$ state (see Fig. 1). A second flash, fired with a time delay $t_{\mathrm{x}}$ chosen beforehand after the first one, can effect another reaction only in those centers which have already completed the first reaction cycle. The turnover induced by the second flash can therefore be used to obtain a measure of the degree up to which the reaction has proceeded during this time interval. After the second flash, sufficient time to finish all reactions is provided before starting the next, identical double flash group. On every fourth step, one $\mathrm{O}_{2}$ molecule is released by each OEC, and so the additional oxygen yield under a regime of double flashes in comparison to the single flash yield gives the value of the progress curve at the time $t_{\mathrm{x}}$. The single flash yield did not vary with dark times between 350 and $450 \mathrm{~ms}$, but decreased outside this range due to incomplete reaction and deactivation, respectively (data shown in ref. 19). For this reason, $400 \mathrm{~ms}$ was chosen as the dark time between single flashes and between double flash groups in all experiments. The flashes of a double flash group were spaced at intervals between 0.056 and $400 \mathrm{~ms}$ chosen beforehand.

Measurements were done at $20^{\circ} \mathrm{C}$ using a Clark type electrode (polarization 


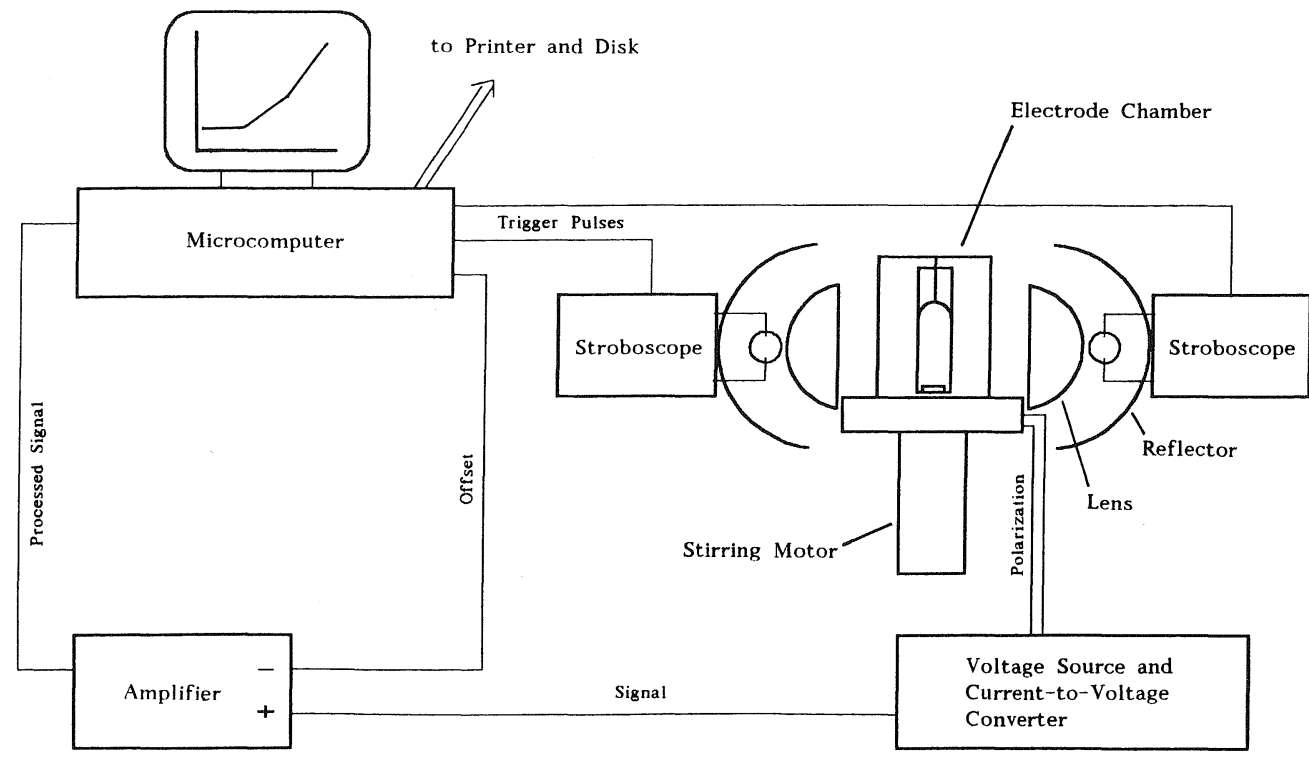

Fig. 2. Scheme of the experimental setup. For details see text.

$-0.8 \mathrm{~V})$ covered by a $12 \mu \mathrm{m}$ teflon membrane. The reaction mixture was stirred magnetically by a glass-coated stirring rod [20]. The apparatus was controlled by a microcomputer (Apple II), triggering the stroboscopes and managing data acquisition via an A/D converter, as shown in Fig. 2. The electrode current was processed by an impedance free current-to-voltage converter (combined with the voltage source in an Applied Photophysics electrochemical processor), and an additional amplifier (PAR ${ }^{\mathrm{TM}} 113$ PRE-AMP). The voltage offset was leveled off by the computer at the amplifier via a D/A converter, so that each measurement consisting of a base-line, a series of 50 single flashes as reference, and a series of 50 double flashes, could span about one half to three quarters of the width of the A/D converter, taking one value per flash and double flash, respectively. Slopes were determined by linear regression, using all but the first ten values of each curve, during which the steady state was reached. Progress curve points normalized to one, $Y\left(t_{\mathrm{x}}\right)$, were calculated by taking the ratio of the slopes under the double- and single-flash regimes after base-line correction.

Before starting the first measurement with a new reaction mixture oxygen was removed by flushing the measuring cell with nitrogen. The same was done before starting further measurements when the $\mathrm{O}_{2}$ concentration became too high to guarantee a smooth signal. All data for a whole progress curve were collected using the same reaction mixture. Approximately half an hour was required for one series of measurements. During this time a significant loss of activity occurred. This was not due to altered kinetics but only to a reduction of the number of active centers, so that the kinetic values related to the actual activity remained constant (Fig. 3). 


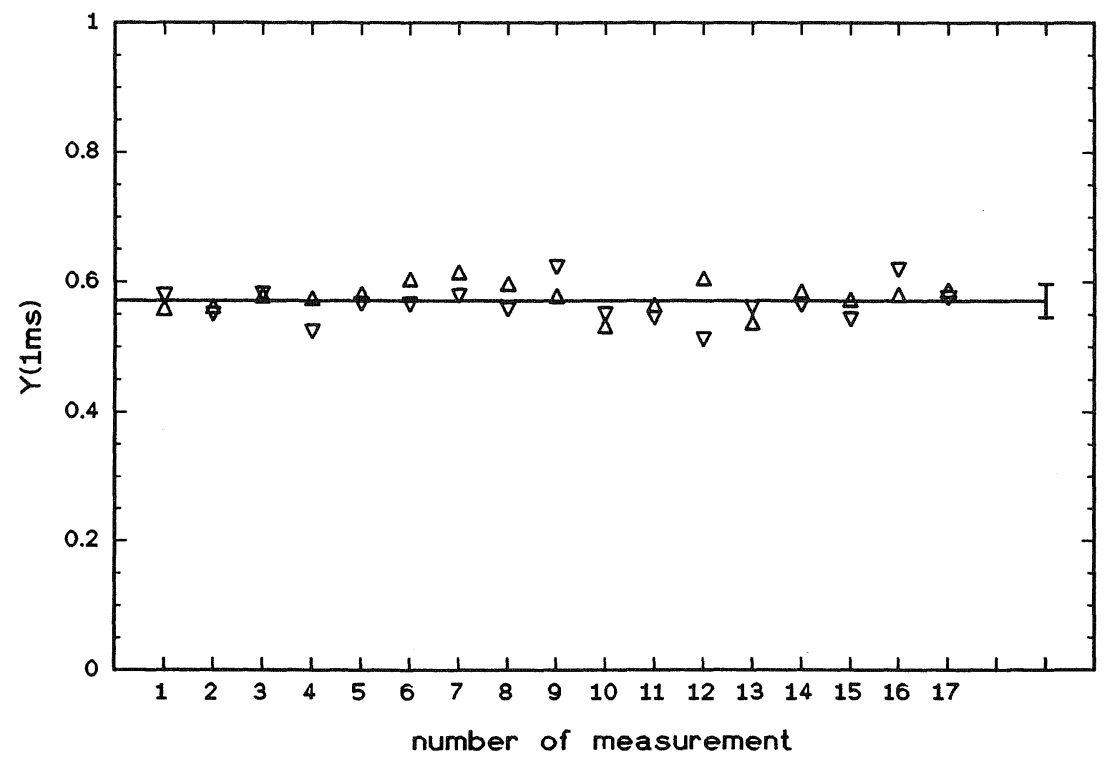

Fig. 3. Time constancy of $Y(1 \mathrm{~ms})$, the $1 \mathrm{~ms}$ value of the kinetics normalized to $1 . Y(1 \mathrm{~ms})$, which lies in the most sensitive region of the progress curves, was determined 17 times from the same sample. $\mathrm{H}_{2} \mathrm{O}$, $\mathrm{p}^{1} \mathrm{H}$ 7.2. $(\Delta)$ First, $(\nabla)$ second experiment. Solid line: mean \pm standard deviation.

All chemicals added to the reaction mixture were in concentration ranges not critical for variation [19].

The ${ }^{1} \mathrm{H}$ content of the $\mathrm{D}_{2} \mathrm{O}$ reaction mixture was determined by NMR spectrometry and was about $0.4 \%$ before and after the kinetic measurements.

\section{RESULTS AND DISCUSSION}

All progress curves were measured three times, each time with a fresh preparation, to prove reproducibility (Fig. 4).

Each progress curve showed exponential kinetics during the first 0.65 to $1 \mathrm{~ms}$. Further progress of the reaction was increasingly slower (Fig. 5). This simple initial time course is astonishing, taking into account the complexity of the system and the fact that four reactions take place in parallel. On the other hand, the slow reaction on the acceptor side of PS II, the passing of the electron from $\mathrm{Q}_{\mathrm{A}}$ to $\mathrm{Q}_{\mathrm{B}}$, might have a great influence on the overall kinetics, namely for the two quicker $S$ state transitions. Furthermore, we have to consider that the $S$ state distribution in the steady state varies with the interval between the flashes, so that different contributions of the single reactions enter the progress curves at different times. Anyhow, the apparent first-order kinetics are consistent with earlier observations [5-8].

In $\mathrm{D}_{2} \mathrm{O}$, the reaction was markedly slower than in $\mathrm{H}_{2} \mathrm{O}$. This was not due to an altered requirement for bicarbonate, which is known to be necessary for electron 


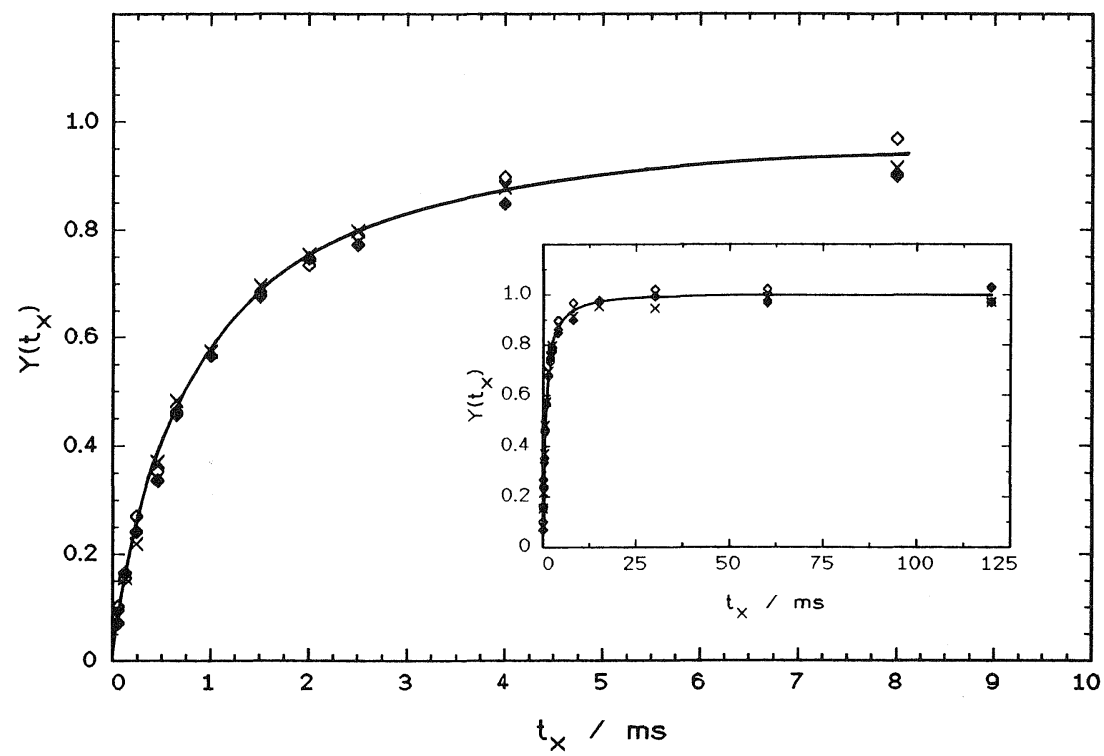

Fig. 4. Reproducibility of kinetic measurements. Three independent preparations. $\mathrm{H}_{2} \mathrm{O}, \mathrm{p}^{1} \mathrm{H}$ 7.2. $(\diamond)$ First, $(\diamond)$ second $(\times)$ third measurement. Inset: longer time scale.

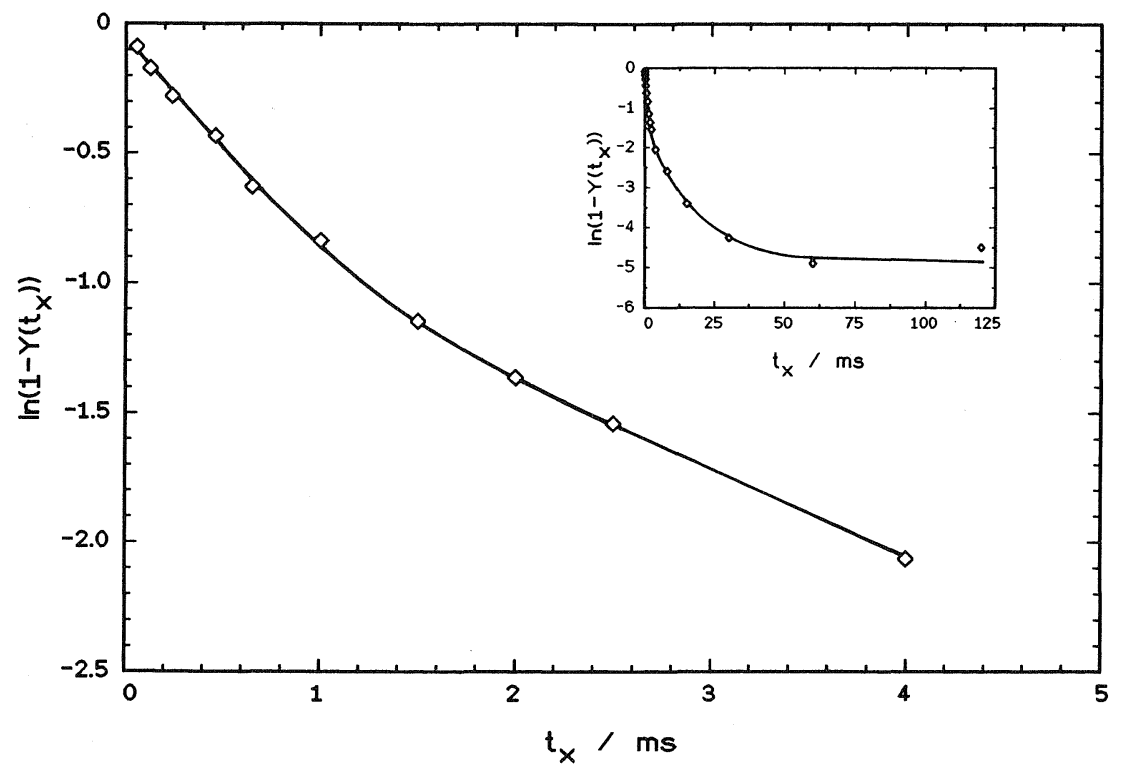

Fig. 5. Semilogarithmic plot of averaged data from the three measurements shown in Fig. 4. 


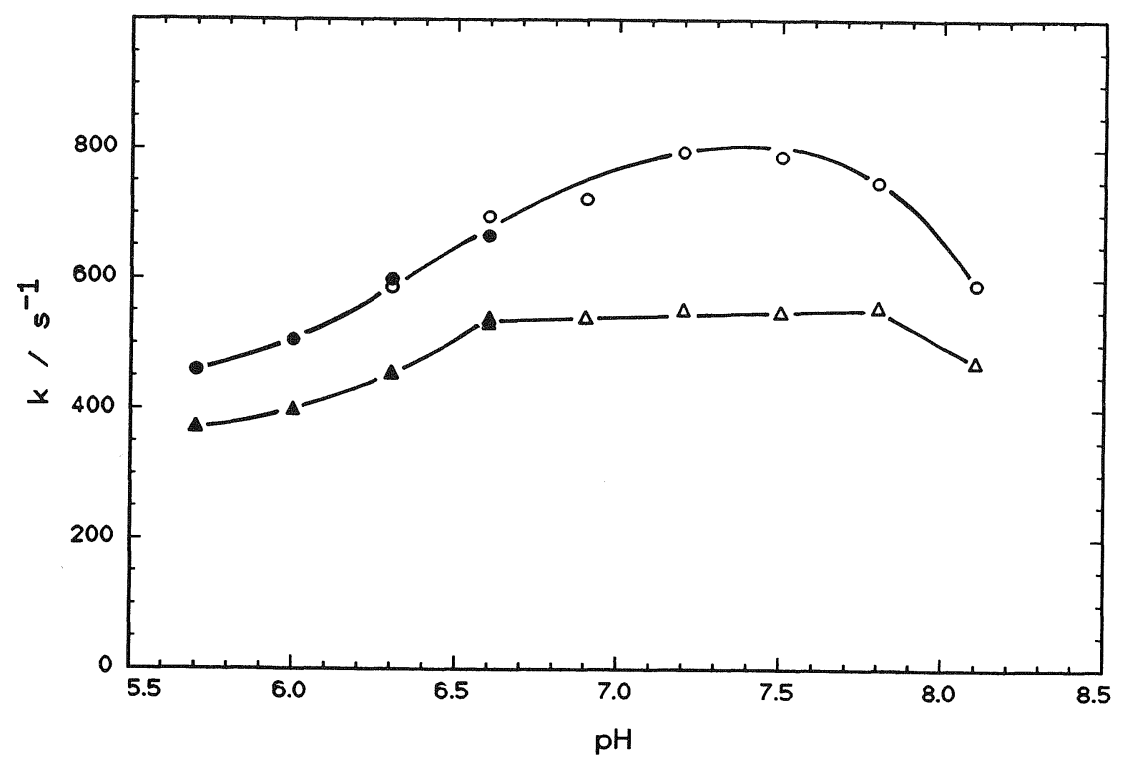

Fig. 6. $\mathrm{pH}$ dependence of the initial first-order rate constant $k$. $(\mathrm{O}, \bullet)$ In $\mathrm{H}_{2} \mathrm{O} ;(\Delta, \Delta)$ in $\mathrm{D}_{2} \mathrm{O}$. Open symbols: $50 \mathrm{mM}$ MOPS buffer. Filled symbols: $50 \mathrm{mM}$ MES buffer. The rate constants were determined by fitting data of three measurements in the semilogarithmic plot by linear regression using the least squares method.

transport through PS II, at least on the acceptor side [21], since the addition of 10 $\mathrm{mM}$ bicarbonate did not fasten the kinetics (data not shown).

The apparent initial first-order rate constants $k$ in $\mathrm{H}_{2} \mathrm{O}$ and in $\mathrm{D}_{2} \mathrm{O}$ at $20^{\circ} \mathrm{C}$ are given in Fig. 6. There is no difference between the data from the two different buffer systems used. The $\mathrm{pH}$ optimum in $\mathrm{H}_{2} \mathrm{O}$ is near $\mathrm{p}^{1} \mathrm{H}$ 7.2, the rate constant being about $800 \mathrm{~s}^{-1}$, in agreement with the literature cited above. In $\mathrm{D}_{2} \mathrm{O}$, a plateau between $\mathrm{p}^{2} \mathrm{H} 6.5$ and 7.8 with a rate constant of $550 \mathrm{~s}^{-1}$ was observed. The apparent kinetic deuterium isotope effect ${ }^{\mathrm{D}} k_{\text {app }}$, given by the ratio of the rate constants in $\mathrm{H}_{2} \mathrm{O}$ and $\mathrm{D}_{2} \mathrm{O}$, proves to be 1.45 in these maxima. On both sides of the plateau, the $\mathrm{D}_{2} \mathrm{O}$ curve seems to be similar to the $\mathrm{H}_{2} \mathrm{O}$ curve, the rate constants being reduced by a factor of 1.2 to 1.3. But the appearance of the plateau itself is a feature very different from the shape of the $\mathrm{H}_{2} \mathrm{O}$ curve.

Since the $\mathrm{D}_{2} \mathrm{O}$ curve does not seem to be shifted with respect to the $\mathrm{H}_{2} \mathrm{O}$ curve, ${ }^{\mathrm{D}} k_{\text {app }}$ is given as a function of $\mathrm{pH}$ in Fig. 7. Apparently, two different deuterium isotope effects on the PS II overall reaction are observed. One small effect is seen outside the plateau region of the $\mathrm{D}_{2} \mathrm{O}$ curve, the other one only in the optimum region of the curves. The reaction exhibiting this effect is almost $\mathrm{pH}$ independent and becomes rate limiting only in $\mathrm{D}_{2} \mathrm{O}$ in the optimum region. It cannot be decided if this reaction in $\mathrm{H}_{2} \mathrm{O}$ shows a rate constant higher than the measured $800 \mathrm{~s}^{-1}$, but in each case ${ }^{\mathrm{D}} \boldsymbol{k}_{\text {app }}$ is higher than or equals 1.45 . 


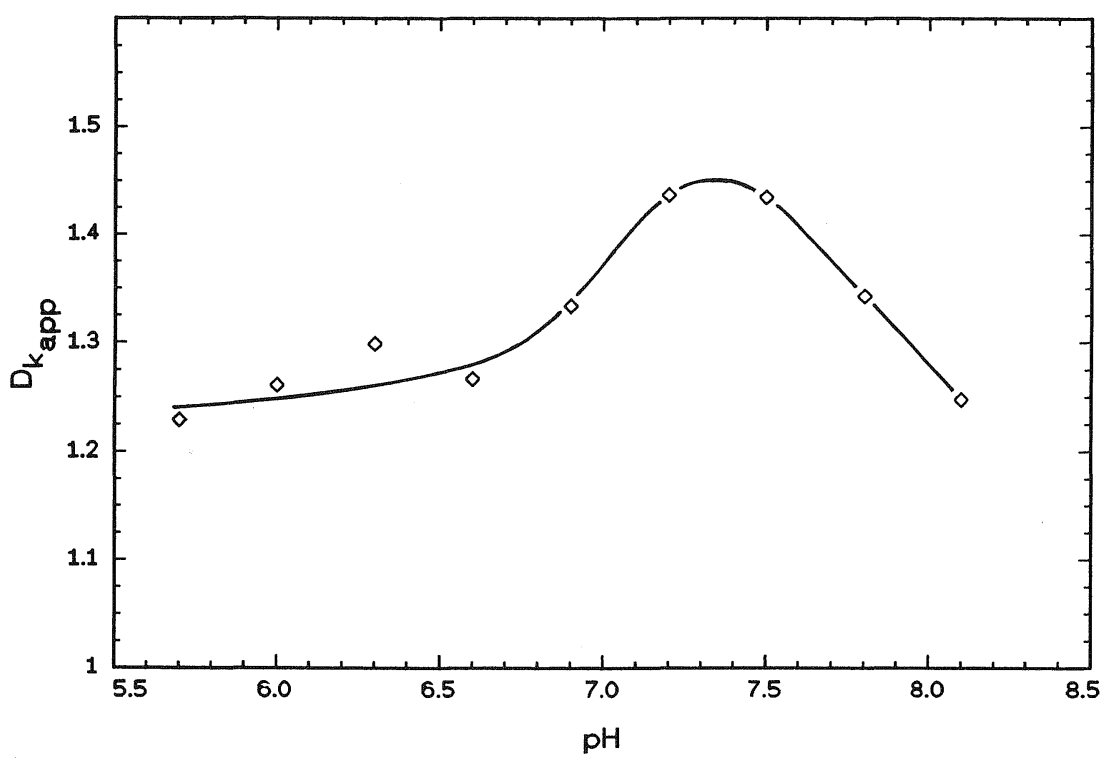

Fig. 7. $\mathrm{pH}$ dependence of the deuterium isotope effect. Rate constants in $\mathrm{H}_{2} \mathrm{O}$ are divided by the rate constants in $\mathrm{D}_{2} \mathrm{O}$ at the same pH. At pH 6.3 and 6.6, values from MOPS and MES buffer were averaged.

In order to obtain information on the transition of the rate constant from $\mathrm{H}_{2} \mathrm{O}$ to $\mathrm{D}_{2} \mathrm{O}$, the reaction was studied in $\mathrm{H}_{2} \mathrm{O} / \mathrm{D}_{2} \mathrm{O}$ mixtures at optimal pH (Fig. 8). A decrease of $k$ is observed over the whole range. There might be a kink in the curve at $90 \% \mathrm{D}$, but because of scattering of the data this is not clear. A possible explanation would be that the small general isotope effect appears already with a low proportion of $\mathrm{D}$, whereas the larger effect, caused by the reaction becoming rate limiting in $\mathrm{D}_{2} \mathrm{O}$ in the $\mathrm{pH}$ optimum, is observed only with a high percentage of deuterium in the medium.

The isotope effects reported here for PS II are of the same order of magnitude as those published for the whole electron transport chain applied to the smaller overall rate constants. They are small with respect to deuterium isotope effects known in organic chemistry, but in this case a complex system of different reactions was studied. Some of those may show isotope effects, others not. For one of the effects only a lower limit may be given. The separated reaction might, however, exhibit a more pronounced difference.

The acceptor-side kinetics obviously have a great influence on all results obtainable under steady state conditions. The rate constants reported for an electron passing from $\mathrm{Q}_{\mathrm{A}}$ to $\mathrm{Q}_{\mathrm{B}}$ after one or two actinic flashes [22] are two- to threefold higher than those which were found for the overall reaction, and they exhibit a different $\mathrm{pH}$ dependence. But it has to be considered that this is still much slower than the two quicker $S$ state transitions and that the exchange of a fully reduced (hydroquinone) molecule at a $\mathrm{Q}_{\mathrm{B}}$ site for an oxidized one (quinone) needs time as 


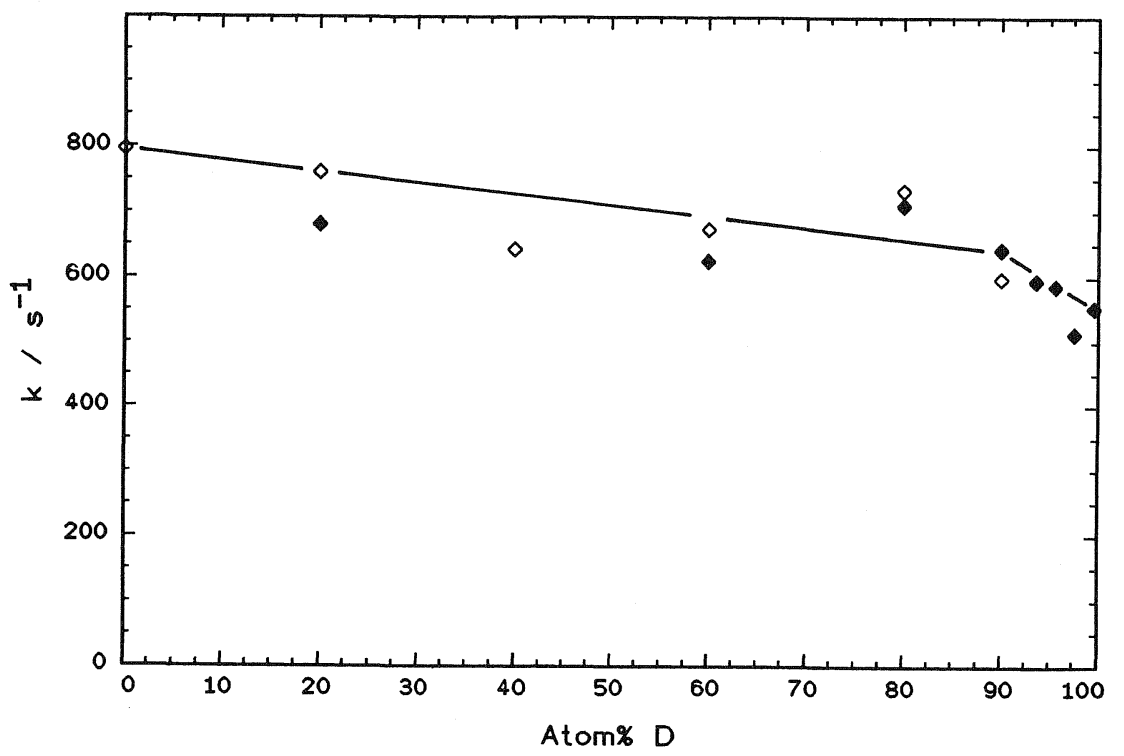

Fig. 8. The rate constants in $\mathrm{H}_{2} \mathrm{O} / \mathrm{D}_{2} \mathrm{O}$ mixtures at $\mathrm{pH}$ 7.2. $(\diamond)$ Thylakoids stored in $\mathrm{H}_{2} \mathrm{O}$; thylakoids stored in $\mathrm{D}_{2} \mathrm{O}$. Data for 0 and $99.6 \% \mathrm{D}$ from Fig. 6. Other points: single determinations. A proposal for a fitting curve is indicated.

well. The results presented here do not allow location of the effects either on the donor side or on the acceptor side of PS II. There may also exist a solvent effect, e.g. on the protein structure due to shorter deuterium bonds. But the appearance of two distinguishable deuterium isotope effects in the overall kinetics should prompt a reinvestigation of the ${ }^{\mathrm{D}} k$ 's of the single $S$ state transitions [23] and other steps of the PS II reaction.

\section{ACKNOWLEDGEMENTS}

We are very grateful to Dr. R. Föll (Institut für Chemische Pflanzenphysiologie der Universität Tübingen) for fruitful discussions, to Prof. A. Trebst (Universität Bochum) for the generous gift of DNP-INT and to Mrs. Phong Tu Nguyen (Institut für Organische Chemie der Universität Tübingen) for performing the NMR measurements.

\section{REFERENCES}

1 G. Renger, Angew. Chem. Int. Ed. Engl., 26 (1987) 643.

2 G.C. Dismukes, K. Ferris and P. Watnick, Photobiochem. Photobiophys., 3 (1982) 243.

3 G.N. George, R.C. Prince and S.P. Cramer, Science, 243 (1989) 789.

4 V.K. Yachandra, R.D. Guiles, A.E. McDermott, J.L. Cole, R.D. Britt, S.L. Dexheimer, K. Sauer and M.P. Klein, Biochemistry, 26 (1987) 5974.

5 V. Bültemann, H. Rüppel and H.T. Witt, Nature (London), 204 (1964) 646. 
6 P. Joliot, M. Hofnung and R. Chabaud, J. Chim. Phys., 63 (1966) 1423.

7 J. Vater, G. Renger, H.H. Stiehl and H.T. Witt, Naturwissenschaften, 55 (1968) 220.

8 R.E. Blankenship, G.T. Babcock, J.T. Warden and K. Sauer, FEBS Lett., 51 (1975) 287.

9 B. Kok, B. Forbush and M. McGloin, Photochem. Photobiol., 11 (1970) 457.

10 J.P. Dekker, J.P. Plijter, L. Ouwehand and H.J. van Gorkom, Biochim. Biophys. Acta, 767 (1984) 176.

11 L.K. Thompson, A.-F. Miller, J.C. de Paula and G.W. Brudvig, Isr. J. Chem., 28 (1988) 121.

12 J. Sinclair and T. Arnason, Biochim. Biophys. Acta, 368 (1974) 393.

13 T. Arnason and J. Sinclair, Biochim. Biophys. Acta, 430 (1976) 517.

14 D.O. Hall, Nature (London) New Biol., 235 (1972) 125.

15 D.A. Walker, Meth. Enzymol., 69 (1980) 94.

16 V. Förster and W. Junge, Photochem. Photobiol., 41 (1985) 183.

17 D.I. Arnon, Plant Physiol., 24 (1949) 1.

18 R. Delosme, P. Joliot and A. Trebst, Biochim. Biophys. Acta, 893 (1987) 1.

19 U. Krohs, Diploma Thesis, Tübingen, 1989.

20 T. Delieu and D.A. Walker, New Phytol., 71 (1972) 201.

21 D.J. Blubaugh and Govindjee, Photosynth. Res., 19 (1988) 85.

22 J.J. Eaton-Rye and Govindjee, Biochim. Biophys. Acta, 935 (1988) 248.

23 T. Arnason and J. Sinclair, Biochim. Biophys. Acta, 449 (1976) 581. 